\title{
EDITORIAL
}

\section{Critical thresholds. Traversing architectural pedagogy, research, and practice}

\author{
Colin Fournier \\ University College London, United Kingdom \\ The Bartlett School of Architecture \\ c.fournier@ucl.ac.uk
}

It is significant that the AASA - Association of Architecture Schools of Australasia (https://aasa.org.au) conference on "Applied Collaborations" took place in Christchurch in the Fall of 2015, not long after the earthquakes that tragically destroyed a major part of the city. Although the physical devastation was extensive and highly traumatic for the inhabitants, it was encouraging to observe that, after an initial phase of shock and paralysis, came an optimistic period of quasi euphoria, a revolutionary spirit, a sense that the city could be radically reinvented instead of being rebuilt merely as a faithful replication of the past.

Rather than aspiring to a reinstatement and perpetuation of the status quo, it was felt that it could emancipate itself from its colonial past, become a better city and, most importantly, that its rebirth could call upon the energy, enthusiasm, self-motivation and generosity of all its inhabitants and truly involve the participation of the community as a whole.

The city, while still licking its wounds and clearing up the debris, went through a vibrant period of recovery and utopian dreaming, a phase when it was felt that anything was possible, that not only could the urban fabric and its supporting infrastructure systems be radically changed but that its governing institutions could also be transformed, as well as the fabric of society as a whole. It was felt that this unique opportunity had to be seized before it was too late. The time had come for a major urban and social mutation.

Although the AASA conference took place several years after the tragedy, the urgency of this pressing original call for collective action of a radical nature could distinctly be felt, albeit with different degrees of intensity, in the interventions of all speakers. The damaged city clearly was, directly or indirectly, the most significant historical and political fact informing the presentations and several of the case studies that were presented were indeed specifically related to the highly innovative community interventions and creative designs that sprang up in Christchurch after the disaster.

In the light of these circumstances, the agenda of the conference called for a critical reexamination of design practice, based on the evidence of applied projects. Three distinct types of responses were made: in urban design and master planning, calls for greater 
community participation and a focus on local bottom-up initiatives; in professional practice, calls for more social engagement and responsibility; in design education, calls for a strong emphasis on "learning by making" and particularly on hands-on "live" projects fully engaged in the problems of the real world, in collaboration with professional design practices, builders and members of the community.

The emphasis on radical experimentation which was prevalent at the AASA conference also has to be seen within the context of what is happening worldwide and not just in Australasia: pushed by profound cultural and geopolitical changes as much as by technological advances, design education as well as professional practice are globally going through a period of rapid evolution. The message that clearly came across at the event is that this evolution could lead to a major paradigmatic shift.

The contributions that have been included in this publication originated from the discussions held at the conference in Christchurch. They are extremely diverse and have been grouped into three distinct chapters, with quite extensive overlaps between them. Comprehensive summaries are given as to the contents of each chapter, so this general introduction is not intended to analyse individual contributions, but rather to highlight the key recurring themes that emerge, in forms that vary from author to author, from the document as a whole.

\section{On the changing nature of collaborative practice}

As several authors point out, we no longer believe in the myth of the designer as solitary genius. Despite the anachronistic survival of the "Starchitect" phenomenon, still promoting an elite of global brands, it is now generally understood that design is a collaborative process involving many participants, including, in various mixes, professionals, educators, students, clients, users and the general public.

This understanding of design as collaborative practice has become commonly accepted and would hardly be worth repeating, were it not for the fact that beyond this change of perspective lies a radical set of deep transformations that are now taking place: what is a stake is not just a quantitative shift of emphasis from singular to plural authorship, but a comprehensive philosophical, social and political reappraisal of the roles performed by different players in the process of design.

As is shown in several of the case-studies, when a "teacher" and a "student" collaborate on a project without being preconditioned by any a-priori definition of their respective roles, the relationship of initiative and power that is revealed in the master/pupil intercourse may well be inverted.

The same is true of collaborations between professional "experts" and "the public", the latter often outperforming the former, not only because members of the public often have a more intimate understanding of local conditions but also because they may, quite simply, be smarter and more qualified to take decisions.

The examples given of various applied collaborations reveal, case after case, that the conventional categories normally used to identify the layering of responsibilities for different players taking part in a design project have, in the past, often been biased, condescending, erroneous and are therefore now largely irrelevant and obsolete.

In other words, true instances of collaboration with "the other" lead us to question all professional hierarchies as much as gender and racial distinctions, cultural preconceptions 
and, ultimately, the social order itself. When taken seriously, collaboration opens up a Pandora's box and is, consequently, a highly political experience.

What the authors also demonstrate is that we collaborate not only with other people but also with objects and, most importantly, with the tools we use. As designers, having finally abandoned the parallel rule and the set square, we now collaborate mainly with software programmes, keyboards and computer screens. Digital tools open up on these screens vast realms of virtual collaborations, on a worldwide basis, that far exceed, not only in terms of numbers, but in terms of quality of information and potential impact, the contributions of the few flesh and blood people that still surround us in the workplace.

One can therefore no longer talk of collaboration without addressing the omnipresent digital partner. Here again, the difference is not merely quantitative: it is a fundamental difference in kind. Collaborating on a design and manufacturing project with an indefatigable robotic device that is far more powerful, precise and versatile than a human being is an experience that totally changes the nature of the task as well as the meaning of collaboration. Even more importantly, collaborating with an artificial intelligence that has not only immense resources of memory and processing power at its disposal but also cognitive abilities that will soon be far superior to ours, are the new challenges we have to face.

Up to fairly recently, we used to consider, somewhat naively, that computers were good primarily for repetitive tasks and humans for creative ones, but this conventional preconception is now seriously in question. Just as the nature of the master/pupil collaboration, as we have seen, is in question, so is that of artificial intelligence versus the human brain.

Paradoxically, collaboration with robotic devices and Al, by immensely expanding our capabilities, challenges our initial critique of the solitary genius and could turn the old metaphor of the "one-man orchestra" into a serious possibility.

\section{On the object of collaborative work and on reality versus fiction}

In cybernetics, the "law of requisite variety" states that any system used to control another system must have at least as much information "variety" as the system it seeks to control. Therefore, large design projects and particularly city planning projects require large multidisciplinary teams in order to match, within their own structure, the complexity of the universe of discourse they have to address. In such design contexts, collaboration is called for as a matter of necessity.

However, in terms of content, virtually all the applied collaborative projects described by the authors in this publication are small "live" projects, usually ephemeral and requiring limited funding. Most of them are light-weight pavilions, temporary performance spaces and prototypical micro-dwellings, such as the excellent designs entered for the solar house competition. All these designs are fascinating and some of them are brilliant. They have been extremely successful exemplary projects, fully adopted by the local communities for which they were made, communities which, in many cases, actively took part in their conception and realisation.

Despite their small size and short time frame, they constituted, in effect, microcosms of the collaborative experience, involving the participation of residents, teachers, students, local tradesmen, builders and manufacturers, shopkeepers, NGO partners, fund raisers, etc. They cut through all the traditional boundaries and constraints that usually plague 
design projects and provided an accelerated experience of what it means to get something done collectively, quickly and successfully, blurring the customary distinction between conception and execution. As such, they were an invaluable learning experience for all concerned.

But, as the authors soberly point out, one also learns about their inherent limitations. As soon as these projects attempted to go beyond the limited scope of their initial terms of reference, as soon as they grew in size and started aiming for long term impacts and larger budgets, they invariably got either aborted or diverted away from the ambitions of their original agenda.

The students, their teachers as well as other participants, all highly engaged emotionally and encouraged by the extraordinary initial success of their incursion into the alleged "real world", suddenly got confronted with a brutal reality check, as if it had all been a dream. As soon as real money and responsibility came in, as soon as longer term interventions were proposed, the group dynamics were taken over by the pragmatics of bureaucracy and "business as usual". The enthusiastic revolutionary spirit of the commons, discredited by the powers that be or undermined by the participants' increasing loss of confidence in their own power, eventually lost momentum.

The moment of truth is bitter. This certainly does not invalidate the live project as such, but there are key political lessons to be learned from these experiences, particularly the fact that practices that are critical and aspire to become movements of resistance against the status quo must ensure that they are not marginalised and given token signs of acceptance through minor distractions. They should not limit themselves to small projects but aim at building up collaborative teams that are robust and durable enough to compete with large commercial firms in tackling large commissions.

There is also a broader point to be made concerning the pedagogical value of "live" projects, which concerns the relative importance given to reality and fiction in architectural design education. The claim is that live projects offer the students a "taste of the real". However, quite apart from the fact that these experiences in social realism remain, at best, on the fringes of reality, one has to face the more philosophical question as to whether, in an educational context, there is more to be learned from reality assuming that there is such a thing - or from fiction. One must be very careful not to discredit the importance of fiction, of the imaginary narrative, as a way of exploring the universe of possibilities that lies before us: fiction, including science fiction, as pointed out by some authors, is an extremely powerful tool of the imagination that may be just as effective, if not more, as a confrontation with what may turn out, in many cases, to be merely an illusion of reality.

\section{On learning by making (LBM)}

The live project is already, on a small scale, an example of the "learning by making" pedagogical approach which is gaining considerable momentum worldwide. LBM, however, is as an approach to learning that is not only applicable to external projects taking place within the community but also to experimental projects that are undertaken internally within the confines of universities and therefore applies to the learning process as a whole. 
It has long been the case that the most successful design schools, internationally, have always been those that have the best workshops and, most importantly, a pedagogical philosophy and intellectual culture that lays emphasis on the primordial importance of encouraging students to make things with their own hands, often very sophisticated physical models and prototypes.

In the last decade, with the exponential technical development and reduction in cost of 3D printers and robotics, LBM has taken on a completely new dimension, with serious implications, as several authors have pointed out, not only in terms of the future evolution of design education and practice but also on the future evolution of the social order and of contemporary society as a whole.

Schools such as the Bartlett in London or the ETH in Zürich are acquiring, for their workshops and design studios, multipurpose machines that are so sophisticated that they enable students to fabricate complex designs on an increasingly large scale, including fullscale prototypes. These machines have increasingly become, as we have noted above, essential collaborators for students, more so than their peers or their teachers or even their desktop computers, software rendering programmes, social network platforms and other addictive digital tools.

But the most important point, beyond the issue of changing modes of collaboration, is the fact that design students are now finally transgressing the age-old semantic boundaries between conception and realisation, between creation and execution, between thinker and maker. They now understand that these conventional dualities are becoming meaningless, since they are finding that many design concepts actually originate from the concrete process of making rather than from the abstract process of thinking. Even those last terms - concrete and abstract - may no longer be relevant in the light of what is now happening in cutting-edge design laboratories.

In effect, we are now questioning some of the most deeply entrenched foundation myths on which civilisation and the social contract are based.

The intimate collaboration between thinker and maker, so intimate that they can become one and the same person, a collaboration between different faculties within oneself, has revolutionary potential. It challenges all accepted notions that we have adopted, at least since the beginning of the industrial revolution, about the division of labour, between white collar and blue-collar workers, a division upon which we have always justified the distinction between ruling class and working class, between those who possess the means of production and those who don't.

This new form of self-collaboration, which has become the crux of contemporary design education, ultimately challenges, within the city, the functional divisions on which the major building typologies and modernist urban zoning concepts were based. If the thinker and the worker are potentially the same person, then it stands to reason that the home, the office, the university and the factory, and possibly even all the other archetypes that form the traditional functions and building blocks of the city, are open to question and could be hybridised in urban entities that will be fundamentally different, both physically and socially, from the city as we know it.

The above themes and their long-term implications are some of the key observations that emerged in the course of the AASA conference on "applied collaborations". They have the immense merit of being observations based on empirical case studies, whereby hypotheses were tested in the context of actual projects rather than relying on purely theoretical considerations. 
The conclusions that emerged identified trends that can be considered to be early symptoms of the positive changes that are taking place within academe, at many different levels, with respect to design education. Together, they clearly lead to an understanding that the design world is in a process of mutation, with greater emphasis being put on collaborative practices, including multidisciplinary collaborations and live projects, but also on the greater impact that new generations of digital computing and manufacturing tools are now having on designers.

In summary, this publication addresses, in essence, two very different kinds of issues related to design education: on the one hand the need for both teaching staff and students to break down the distinction between learning and doing, between academe and the outside world; and on the other hand the need to be responsive to those cutting edge advances in technology that are now profoundly altering the way we think and operate.

As the papers demonstrate, these issues are complementary and together contribute to radically new forms of practice. It is encouraging to note that it was the wounded city of Christchurch, still in a process of recovery, that offered the AASA conference the opportunity to raise these radical issues through the extraordinarily inventive, playful and empowering design projects that took place within it.

London, $12^{\text {th }}$ of March, 2017

\section{To cite this article:}

Fournier, C. (2017), Critical thresholds. Traversing architectural pedagogy, research, and practice, The Journal of Public Space, 2(3), Special Issue, I-6, DOI: 10.5204/jps.v2i3. 106

This article has been accepted for publication in The Journal of Public Space. Please see the Editorial Policies under the 'About' section of the journal website for further information.

This work is licensed under a Creative Commons Attribution - Non Commercial 4.0 International License https://creativecommons.org/licenses/by-nc/4.0/ 